\title{
Acto de confusión generador de Competencia Desleal. Análisis desde el derecho sustancial
}

Act of confusion generating Unfair Competition. Analysis from substantial law

Pablo Andrés Delgado Peña ${ }^{1} \underline{\text { ORCID }}$

Fecha correspondencia:

Recibido: 30 de octubre de 2019.

Revisión: 13 de febrero de 2020.

Aceptado: 2 de marzo de 2020.

Forma de citar:

Delgado, Pablo Andrés. "Acto

de confusión generador de

competencia desleal: Análisis

desde el derecho sustancial."

Revista CES Derecho. Vol. 11, №. 1,

enero a junio de 2020, 117-133.

Open access

Términos de uso

Licencia creative commons

Etica de publicaciones

Revisión por pares

Gestión por Open Journal System

DOl: http://dx.doi.org/10.21615/

cesder.11.1.6

ISSN: 2145-7719

Sobre los autores:

1. Abogado de la Universidad

Autónoma de Bucaramanga

UNAB, PhD en Derecho de

la Universidad Carlos III de

Madrid España, Especialista en

Gerencia de Recursos Energéticos

de la UNAB, Especialista en

Propiedad Industrial, Derechos

de Autor y Nuevas Tecnologías

de la Universidad Externado

de Colombia, Especialista en

Seguros de la UNAB, con Curso

de Especialización en Propiedad

Intelectual de la Universidad

Castilla La Mancha - Toledo

España, Especialista en Derecho

\section{Resumen}

El presente artículo integra un análisis del acto de confusión como generador de competencia desleal, estableciendo su noción, elementos, contenidos y diferencia con el acto de imitación generador de competencia desleal, con el cual se ha presentado varias indebidas relaciones y que se han definido en sedes judiciales.

El acto de confusión que se presenta en el mercado afecta la libre y leal competencia, atentando principalmente contra el instituto de la libre competencia, contra los consumidores y comerciantes, dentro de un contexto de mercado.

Por ello, la ley de competencia desleal busca repeler y sancionar estos actos, propendiendo por un equilibrio dentro del mercado, por una competencia libre y que en sus apariciones esté enmarcada en los principios de ética y buena fe comercial.

A partir de la revisión normativa nacional, supranacional y de la doctrina, se desarrolló el proyecto referido a la "Hermenéutica del acto de confusión generador de competencia desleal en Colombia: un estudio desde el derecho sustancial y procesal", al interior del grupo de Investigación "Hermenéutica Jurídica", profundizando en los puntos esenciales para su correcta interpretación. Por ello, del evidente desconocimiento en el área, se dio como resultado de la investigación la generación del presente artículo, que se concreta en proporcionar información especializada en la materia, para un público universal, integrado por estudiantes de derecho, abogados y empresarios, con miras a dar claridad, publicidad y apoyo en sus decisiones.

Palabras claves: Acto de confusión, competencia desleal, actos desleales, buena fe en el mercado, proceso jurisdiccional de competencia desleal.

\section{Abstract}

This document integrates an analysis of the act of confusion that generates unfair competition, establishing its notion, elements, contents and difference with the act of imitation, with which there have been some conflicts of interpretation and that have been defined in the courts. 
Público y Derecho Penal de la UNAB. Profesor

e Investigador de la

Facultad de Derecho de la

Universidad Autónoma de

Bucaramanga UNAB.
The act of confusion that arises in the market affects free and fair competition, which mainly affects the institute of free competition, against consumers and merchants, within a market context.

Therefore, the law of unfair competition seeks to repel and punish these acts, seeking a balance within the market, free competition and that is framed in the principles of ethics and good commercial faith.

Based on the national normative, supranational and doctrine review, the project referred to the "Hermeneutics of the confusion act generating unfair competition in Colombia: a study from substantial and procedural law", was carried out within "Hermeneútica Jurídica" a research group of the "Universidad Autónoma de Bucaramanga", deepening the essential points for its correct interpretation. Therefore, the obvious lack of knowledge in the area resulted in the generation of this writing, which is specified in providing specialized information on the subject, for a general public, consisting of law students, lawyers, businessmen and any another interested, that have direct or indirect participation in the market, with a view to clarity, publicity and support their decisions

Keywords: Disloyal competition, unfair acts, confusion act, good faith in the market, jurisdictional process of unfair competition.

\section{Introducción}

A diferencia de la creencia generalizada según la cual la competencia desleal busca proteger principalmente los intereses de los comerciantes, debe aclararse que, por el contrario, se ha establecido que el bien jurídico protegido es la "competencia" misma como instituto jurídico independiente, de manera que la libre competencia adquiere relevancia en la medida que se tienen como fin primordial de la normativa de competencia desleal.

Si estuviéramos en un plano de mercado en el que se respetaran las reglas generales de la libre y leal competencia tendríamos una competencia en la que resultarían beneficiados los intereses de los consumidores, comerciantes y en general, todos los participantes en el mercado, sin embargo, esta hipótesis no se presenta ni presentará en Colombia, dadas las condiciones particulares de nuestro mercado, donde la influencia de factores tales como el trabajo informal, las tasas de desempleo, las evasiones tributarias, infracciones marcarias, usurpación de signos distintivos, imitaciones de productos, falsificación de bienes, piratería mercantil, contrabando, entre otros, hacen necesaria la intervención del Estado, para que, a través de la normativa de competencia desleal, fije principios éticos y reglas de conducta en el mercado, que demandan comportamientos de buena fe, usos horados y honestos en las actuaciones que se realicen por todos los participantes del mercado.

Hoy, tenemos vigente la Ley 256 de 1996, que derogó los artículos 75 y siguientes del Código de Comercio colombiano, la cual entró a regular la conducta de los participantes en el mercado, enunciando de manera ejemplificativa y no taxativa algunos actos que se consideran contrarios a la buena fe mercantil y usos honestos, y estableciendo limitación en las actuaciones que se generen dentro del tráfico mercantil, derivando las consecuencias jurídicas de su incumplimiento, las cuales podrán verse materializadas a través de las respectivas acciones administrativas y jurisdiccionales que procedan. 
No puede dejarse al margen que la norma citada trae en su artículo 7 un principio-norma que es la cláusula de prohibición general de competencia desleal que tienen como finalidad ser objeto para la interpretación general y sistemática de la Ley 256 de 1996.

Del proyecto referido a la "Hermenéutica del acto de confusión generador de competencia desleal en Colombia: un estudio desde el derecho sustancial y procesal", realizado al interior del grupo de Investigación "Hermenéutica jurídica" de la Universidad Autónoma de Bucaramanga; y del desarrollo del Doctorado en Derecho de la U Carlos III de Madrid realizado por el autor (con apartes de la tesis doctoral), surge este documento, cuyo objeto se centrará entonces, en determinar cuáles son los elementos y requisitos constitutivos del acto de confusión generador de competencia desleal para su verificación en Colombia, a partir de la interpretación sistemática de la Ley 256 de 1996, el C.G.P. y la integración con los pronunciamientos de las autoridades jurisdiccionales, lo cual nos lleva a crear un contenido objetivo del instituto jurídico bajo análisis, el cual no se deduce de la norma en sí misma como se mencionó, aclarando que se hará una especial referencia a la normativa y doctrina española, atendiendo a que nuestra ley de competencia desleal integra varios elementos copiados de la norma original española de competencia desleal (Ley 3 de 1991), y por ello, estas interpretaciones y doctrina han sido acogidas por los jueces y autoridades colombianas.

\section{Metodología}

El proceso de investigación referido tiene una base descriptiva, con un componente hermenéutico analítico, sustentado en el análisis de textos, como técnicas de investigación, que involucra tanta normativa nacional, doctrina y jurisprudencia; así como, algunos referentes españoles.

\section{Competencia desleal por actos de confusión}

\section{Noción de la confusión dentro del ámbito de competencia desleal en Colombia y España}

En general, los supuestos de competencia desleal deben enmarcarse en aspectos propios que configuran y caracterizan el fenómeno. La competencia implica la posibilidad de concurrir y participar en un mercado en igualdad de condiciones, las normas sobre competencia desleal procuran proteger a los competidores frente a conductas de sus colegas que van en contra de las costumbres mercantiles y que intentan privarlos de parte de su mercado y también a los terceros en general que se ven afectados por dichas conductas. Por lo tanto, para que esa deslealtad exista basta que la actuación en cuestión sea incorrecta y pueda perjudicar a cualquiera de los participantes del mercado (Cardona, 2009); en el evento de presentarse un acto de esta naturaleza, corresponde al intérprete de la norma y garante de la administración de justicia analizar acuciosamente las variables que se presentan y la forma correcta para solucionar la controversia.

En Colombia, autores como MAURICIO VELANDIA se han referido al acto de confusión como aquel acto que no permite al consumidor identificar la verdadera procedencia de un producto (Velandia, 2001). Así mismo, menciona que "el acto de deslealtad por confusión se presenta cuando existe error acerca de la procedencia empresarial de los productos puestos a disposición del mercado (...) la confusión se presenta cuando existe error por acción o por omisión acerca de la procedencia empresarial. (Velandia, 2001). 
Sobre la noción de confusión y la relación entre la regulación de ésta dentro del régimen en materia de marcas y la competencia desleal, el profesor JOSÉ MASSAGUER ha mencionado que: "la confusión si quisiéramos definirla en términos generales, y naturalmente necesitados de precisión, concreción y afinamiento, confusión es el error sobre la procedencia empresarial de productos, de un servicio, de un establecimiento o de una determinada actividad empresarial, y así considerada es una noción común al derecho de marcas y el derecho contra la competencia desleal, en los que juega un papel distinto, pero extraordinariamente próximo, estructuralmente es distinto del papel que se les asigna, pero funcionalmente en los dos casos es el efecto, si se prefiere, la circunstancia, la probabilidad que va a determinar lo indebido de una conducta, lo indebido del registro de una marca solicitada, lo indebido de la utilización de una marca o signo distintivo no registrado, lo indebido de la utilización de un medio de identificación de prestaciones, actividades o establecimientos realizado en el mercado. Pero más allá del objeto, es decir, de que es aquello cuya utilización puede dar lugar a la confusión con que, la confusión es un concepto común en ambos ámbitos; en marcas lo que se trata es de establecer el alcance de la protección de una marca registrada, en competencia desleal el reproche de deslealtad de una determinada conducta. Pero que significa confusión, en realidad, es lo mismo en uno y otro ámbito, y qué es confusión, después de una jurisprudencia que ya cuenta con más de cien años y está plenamente consolidada, tenemos que confusión, generalmente aceptado, es lo mismo en materia de marcas y en materia de competencia desleal y que son distintas las modalidades de falsa representación de la realidad sobre la procedencia empresarial de un producto o servicio de una actividad empresarial o de un establecimiento que caben dentro de esta noción" (Massaguer, 2017).

Dentro del ordenamiento colombiano sobre la competencia desleal, la Ley 256 de 1996 establece el acto de confusión en los siguientes términos:

ARTÍCULO 10. ACTOS DE CONFUSIÓN. En concordancia con lo establecido por el punto 1 del numeral 3 del artículo 10 bis del Convenio de París, aprobado mediante Ley 178 de 1994, se considera desleal toda conducta que tenga por objeto o como efecto crear confusión con la actividad, las prestaciones mercantiles o el establecimiento ajenos.

Respecto a la legislación española se encuentra que la legislación colombiana no consagra, en el precepto sobre el acto de confusión, el siguiente apartado que sí se integra en la Ley de Competencia Desleal Española, art. 6: "El riesgo de asociación por parte de los consumidores respecto de la procedencia de la prestación es suficiente para fundamentar la deslealtad de una práctica.". Sin embargo, realizando una hermenéutica amplia, podría decirse que el anterior texto excluido podría tenerse como incluido en el primer párrafo del artículo 10 de la Ley de Competencia Desleal Colombiana, para de esta manera no dejar por fuera el riesgo de asociación que crea confusión.

Como puede evidenciarse, la anterior normativa parte de la prohibición de los actos de confusión se encuentra contenida en el Convenio de la Unión de París en el que se dispuso en su artículo 10 bis Al respecto dicha normatividad establece: "(...) 3) En particular deberán prohibirse: i) cualquier acto capaz de crear una confusión, por cualquier medio que sea, respecto del establecimiento, los productos o la actividad industrial o comercial de un competidor; (...)". Pero, tanto la norma supranacional como la nacional no permite extraer de manera clara una definición del acto de confusión, razón por la cual, la autoridad en Colombia ha tenido que acudir a interpretaciones doctrinales como las anteriormente mencionadas. La deficiencia en la 
estructura de la norma en mención ha sido objeto de críticas por parte de la doctrina entre estos (Velandia, 2008), "de la lectura desprevenida del mismo no se puede extraer gran significado, pues el texto colombiano no es generoso ya que sólo se limita a señalar que los actos de confusión resultan ser desleales, sin explicar a qué se refiere con ello".

De todo lo anterior puede extraerse que la confusión vista como acto positivo es un fenómeno esencial, que adquiere gran relevancia en el ámbito o sistema jurídico de marcas y en el sistema de represión de la competencia desleal. Así las cosas, se evidencia que en el sistema jurídico colombiano de signos distintivos y concretamente de marcas, la confusión determina el ámbito de protección de los signos distintivos registrados al tener presencia tanto en los conflictos registrales, que se traban con ocasión de posibles oposiciones al trámite administrativo de registro marcario, como en aquellos casos donde se hace uso de los recursos jurídicos de apelación; pero, aparte del trámite mismo marcario, también adquiere vigencia el fenómeno de la confusión con el ingreso de un nuevo signo distintivo al mercado para identificar productos y servicios de un proveedor, que se asimila a otra ya existente y en el peor de los casos a otro ya registrado previamente por persona natural o jurídica diferente, lo cual genera un estado de inseguridad jurídica y comercial, que correlativamente lleva a una posible ruptura o contienda de mercado, en el que no solo son intervinientes los diferentes titulares de los signos en conflicto, sino que además los efectos se extienden a los consumidores (Massaguer, 2017).

Ahora, en tratándose de la represión de la competencia desleal, el riesgo de confusión y la confusión misma están considerados como elementos esenciales de la deslealtad, en donde el juicio de reproche está ligado directamente o referida a actuaciones en las que intervienen en su ejecución y afectación signos distintivos, así como medios de identificación de productos, servicios y establecimientos que puedan resultar implicados.

\section{Consideraciones previas acerca del riesgo de confusión: Noción de riesgo de confusión}

Ahora bien, entendida la confusión como el resultado de una conducta desleal debe resaltarse que la normatividad a la que se ha hecho mención, al referirse sobre el concepto de confusión, establece la prohibición tanto del acto generador del resultado como del acto capaz de generar confusión en el consumidor. Por tal razón, se ha desarrollado el concepto del riesgo de confusión, como un aspecto importante dentro de la normatividad de la competencia desleal y derecho de marcas, y como un elemento del acto objeto de reproche que permite determinar su idoneidad para generar la confusión en el consumidor.

"El riesgo de confusión es una de las figuras centrales del derecho de la competencia desleal y del derecho de marcas. En efecto, al surgir en el siglo XIX En Europa el derecho de la competencia desleal el protagonismo de esta incipiente rama jurídica fue asumido por la represión de los actos de confusión. En el ordenamiento español los actos de confusión constituían una de las modalidades de competencia ilícita contemplados por la ley de propiedad industrial de 1902. En el vigente derecho español, los actos de confusión se tipifican en la letra B) Del artículo sexto de la ley General de publicidad y en el artículo seis de la ley de competencia desleal. Por otro lado, es indudable que una de las claves fundamentales del derecho de marcas es la figura jurídica del riesgo de confusión. En efecto, el riesgo de confusión de una marca con otro*es un mecanismo que 
opera en diversos sectores del sistema de marcas. Una de las prohibiciones básicas que pueden bloquear el acceso de una marca al registro consiste en la existencia de un riesgo de confusión de la marca solicitada con una marca anterior [cfr. letra b) Del artículo 4.1 de la directiva 89-104-CEE y letra B) del artículo 6.1 de la ley española de 2001]. Al mismo tiempo, el parámetro fundamental que determina el ámbito del derecho subjetivo sobre la marca estriba en la existencia del riesgo de confusión con otra marca o signo distintivo [cfr. letra b) Del artículo 5.1 de la directiva 89-104-CEE y letra B) del artículo 34.2 de la ley española de 2001].

La europeización de la figura del riesgo de confusión. En la jurisprudencia del Tribunal de Justicia de las Comunidades Europeas deben contraponerse dos etapas con respecto al influenciamiento de la figura del riesgo de confusión. A saber: 1. En una primera etapa el Tribunal de justicia tú que correspondía exclusivamente a los Tribunales nacionales de los estados miembros el apreciar de acuerdo con sus propios criterios de existencia de un riesgo de confusión entre marcas. En este sentido se pronunció expresamente la sentencia de 30-11-1993 que falló el caso "Deutsche Renault AG contra Audi AG" (Asunto C-317-1991=Rec. 1993, pp. I-6227 y ss). 2. En una segunda etapa el Tribunal de justicia enjuicia el riesgo de confusión desde una perspectiva comunitaria al interpretar las normas contenidas en la letra B) Del artículo 4.1 y en la letra B) del artículo 5.1 de la directiva 89-104-CEE. En esta segunda etapa se encuadran los siguientes sentencias del Tribunal de justicia de las comunidades europeas:v) La sentencia del Tribunal de justicia de seis-10-2005 que falló el caso "Thomson Life" (Asunto C-120-04 =Rec. 2005, pp. I-8551 y ss). En esta sentencia el Tribunal complementa la doctrina sentada en el caso "Matratzen", Al contemplar el supuesto particular de que el signo constitutivo de una marca posterior ocupé en una marca compuesta anterior "una posición distinta y autónoma"(Fernández, C., Otero, J., y Botana, M., 2013).

Para el caso de Colombia, ésta es una particularidad especial que no traía la anterior legislación colombiana, por lo que convierte este acto en un tipo de peligro (de riesgo) y no necesariamente de resultado, al generar la posibilidad de hacer un juicio de reproche al simple riesgo de confusión, sin que efectivamente se materialice la conducta que traerá como efecto la confusión en el público consumidor. "La deslealtad se produce, por tanto, en cuanto se da la identidad o similitud de los distintos elementos que se utilizan para diferenciar a las empresas, a sus actividades o a sus productos y no desaparece por el hecho de que el error se desvanezca se observan simultáneamente ambas imágenes o se escuchan seguidamente los dos sonidos, pues el consumidor no puede realizar habitualmente estas comparaciones por no tener ante sí todos los elementos." (Uria, R., y Menendi, A. 2006). Dicho en otras palabras, basta que la actuación del agente participante en el mercado genere el riesgo de crear confusión (error), aun cuando no se consume la conducta, la cual podrá ser de tracto sucesivo o realizado en un solo acto de manera instantánea.

La Superintendencia de Industria y Comercio de Colombia -SIC- en sentencia N 001 de 2006, ratificó tal interpretación al sostener que para configurarse la deslealtad de la confusión es suficiente determinar si existe riesgo de confusión en los consumidores, respecto del producto o servicio, el establecimiento o la prestación ofrecida, debiéndose probar que el consumidor crea equivocadamente que los productos o servicios que "se le ofrecían provenían del demandado, o que su parecido o semejanza hubieran hecho creer al consumidor que ambos tenían la misma procedencia empresarial, o 
que ambos oferentes tuvieran alguna relación que los vinculara" (Sentencia Nº 001 de 2006 de la Superintendencia de Industria y Comercio de Colombia, de 4 de enero de 2006, Expediente No. 03081970).

Finalmente, esta concepción expuesta sobre el riesgo real o relevante de confusión debe también abordarse desde las diferentes categorías de confusión que, si bien se refieren a la consumación o resultado real del acto de confusión, pueden también entenderse como las categorías de riesgo de confusión que pueden configurarse por una determinada conducta que sea considerada idónea para generar el acto desleal.

\section{Categorías de confusión}

Respecto a las categorías de confusión se encuentra que existen diferentes posturas frente a su clasificación. Por un parte se encuentra lo planteado por un sector de la doctrina (Portellano 2001) para el que existen dos líneas definitorias del acto de confusión; una interpretada en sentido estricto y la otra en sentido amplio.

Se presenta la confusión en sentido estricto cuando se genera "un error acerca de la identidad de la empresa de la que procede la prestación, esto es cuando se considera que ambas prestaciones proceden de la misma empresa" (Portellano 2001). Dentro de la confusión en sentido estricto encontramos la siguiente subdivisión:

a) La confusión directa o inmediata, que se presenta "cuando el consumidor, debido a la identidad o gran similitud de las prestaciones, considera que se trata del mismo signo distintivo (v.gr., Philips/Philip)"

b) La confusión indirecta o mediata, en materia de signos distintivos se presenta "cuando el consumidor aprecia que son dos signos distintivos, pero su parecido le lleva a entender que ambas prestaciones proceden de la misma empresa, imputando las diferencias a que se trata de una modernización del antiguo producto, aun nuevo miembro de la familia de productos o a que los productos proceden de diferentes sucursales o establecimientos (v.gr., Pilymeral/Polymerin) (Portellano 2001).

Por otra parte, estamos frente a la confusión en sentido amplio cuando "el consumidor no sufre una confusión acerca de la identidad de la empresa de procedencia, sino que aun siendo consciente de que las dos mercancías tienen una procedencia empresarial diferente, supone equivocadamente que ente las empresas oferentes de cada una de las prestaciones existen relaciones económicas, comerciales o de organización" (Portellano 2001).

Es preciso señalar que estas clases de confusión no se presentan exclusivamente con los signos distintivos, sino que, por el contrario, extienden su contaminación y gran relevancia a las creaciones materiales, y en especial, a los diseños industriales; clases de propiedad industrial que hoy por hoy ha tomado mayor importancia debido a los avances en esta área y la representación económica que evidencia en los mercados de América Latina.

A partir de esta clasificación se plantea la categoría del riesgo de asociación, que es una figura que trae expresamente la ley de competencia desleal española, en la cual confluyen tanto el riesgo de confusión indirecta como el riesgo de confusión en sentido amplio. Al analizar el artículo 11.2 de dicha ley, que establece: "No obstante, la imitación de prestaciones de un tercero se reputará desleal cuando resulte idónea 
para generar la asociación por parte de los consumidores respecto a la prestación o comporte un aprovechamiento indebido de la reputación o el esfuerzo ajeno. Debe tenerse en cuenta que el artículo 11.2 mencionado está haciendo referencia al acto de imitación, que su existencia como acto generador de competencia desleal presupone una relación con creaciones materiales (el producto en si mismo) y no se relaciona de manera alguna con confusiones derivadas de creaciones formales (signos distintivos, que de presentarse confusión sobre estos, el precepto aplicable será el art. 6 de la ley de competencia desleal española); para un mayor contexto, se evidencia que el art 11.2 referido menciona de manera textual la figura de la asociación la cual debe entenderse como la relación mental que hace el consumidor de un producto (creación material) con un origen empresarial, que en la realidad no corresponde, es decir, no es correcto, razón por la cual se considera una confusión indirecta o en sentido amplio. En esta instancia pueden establecerse dos situaciones de asociación dentro del acto de imitación a saber: i) el consumidor considera erradamente que, frente a dos productos que reconoce son diferentes, pero por su parecido y coincidencias, considera que proceden del mismo origen empresarial, es decir, que la misma empresa fabrica esos dos productos, cuando ello no corresponde a la realidad; o ii) el consumidor sabe que ese producto (creación material) proviene de un origen empresarial distinto a la empresa reconocida por estos productos; pero que, por sus coincidencias y parecido en el diseño, estructura y otros elementos del producto, considera debe existir algún tipo de relación jurídica, comercial, contractual o de grupo empresarial entre la empresa reconocida y el origen empresarial real, sin ser esto cierto.

Continuando con el análisis del mencionado artículo 11.2 podríamos manifestar que se encuentra un vacío al no contemplarse el riesgo de confusión directa, el cual estaría subsanado o subsumido por el el principio ad maiori ad minus, según el cual, ha de considerarse desleal lo más dañino (riesgo de confusión directo), toda vez que la ley ampara como desleal lo menos dañoso (riesgo de confusión indirecto). En esta confusión directa, dentro del acto de imitación generador de competencia desleal, el consumidor confunde y elige un producto considerando que es el de su elección habitual, cuando realmente no es y no corresponde al origen empresarial de su predilección.

Por su parte, en la norma que regula la competencia desleal en Colombia, no se hace referencia explícita al riesgo de asociación, a pesar de tener elementos comunes con la ley de competencia desleal española, sin embargo, en su artículo 14 se ejemplifica en su texto un caso de riesgo de asociación, el cual es concretamente la consideración de deslealtad al establecer "... No obstante, la imitación exacta y minuciosa de las prestaciones de un tercero se considerará desleal cuando genere confusión acerca de la procedencia empresarial de la prestación o comporte un aprovechamiento indebido de la reputación ajena" (Articulo 14 e la Ley 256 de 1996). En este caso en particular, se incorporan elementos de la figura de la asociación, sin que se mencione tal de manera expresa, al considerar la deslealtad derivada de la confusión relacionada con la procedencia empresarial de la prestación, entendiéndose a la prestación como creación material (producto). Esta redacción de la norma colombiana podría permitir una interpretación que posibilite la existencia de confusiones indirecta y en sentido amplio, pero sobre creaciones materiales, como se explicó anteriormente. 
Otro sector de la doctrina concibe la confusión solo en un sentido amplio, entre la que se encuentra la confusión directa, como aquella en donde se confunde la identidad del empresario productor, y la indirecta o asociación, como aquella en donde se cree que existe una relación entre dos empresas; "la confusión visual, la confusión causada por la identidad o similitud de los signos, sean estas palabras, frases, dibujos, etiquetas o cualquier otro por su simple observación. (...) la confusión auditiva. Esta confusión se da cuando la pronunciación de las palabras tiene una fonética similar. Esta pronunciación puede ser correcta o deformada, lo que importa es cuál es la pronunciación que una parte considerable del público efectúa e las palabras en cuestión. (...) la confusión ideológica expresada en las siguientes manifestaciones: La similitud conceptual de palabras es la que se deriva del mismo o parecido contenido conceptual de la marca. Es la representación o evocación a una misma cosa, característica o idea la que impide al consumidor distinguir una de otra. La similitud conceptual de dibujos ocurre cuando las marcas estén formadas por dibujos que representan una misma cosa. La similitud conceptual entre una palabra y un dibujo es la que existe entre una palabra y el dibujo que representa esa palabra". (Martínez 2009).

Esta última postura fue acogida por la jurisprudencia de la Superintendencia de Industria y Comercio colombiana-SIC-, entre otras, en la sentencia a No 001 de 2011, con base en consideraciones de la doctrina y la jurisprudencia del el Tribunal de Justicia de la Comunidad Andina, en la que se clarificó que el acto desleal de confusión incluye tanto los casos en los que "el consumidor, al adquirir un producto, piensa que está adquiriendo otro - de su predilección- (confusión directa), como aquellos en los que se presenta el denominado riesgo de asociación, que se produce cuando el consumidor reconoce la diferencia entre los productos o servicios de que se trate y su distinto origen empresarial, pero de algún modo se le ha llevado a pensar que existe una relación entre ambas [empresas], ya sean vínculos comerciales, contractuales, pertenencia al mismo grupo empresarial, fusiones, escisiones, entre otros, (Confusión indirecta)" (Sentencia N001 de 2011 de la Superintendencia de Industria y Comercio de Colombia, de 12 de enero de 2011, Expediente 04060765).

Para evidenciar esta última clase de confusión -indirecta-, no basta el simple capricho de un consumidor, sino que debe precisarse y probarse que los elementos, presentación del producto, disposición de signos o diseño del empaque, generan en un grupo de consumidores -no solo en un sujeto- la inminente idea errónea de un origen empresarial diferente al real, lo que puede afectar la libre decisión que una de las garantías del consumidor, en tanto que tiene la posibilidad de preferir un producto a otro, por la confianza, fama, reconocimiento, posicionamiento, etc., con que asocia una determinada marca o empresa junto con el status de calidad o prestigio que ofrece el producto y por el cual estaría dispuesto a pagar un precio superior (Sentencia No. 006 de la Superintendencia de Industria y Comercio (en adelante "SIC"), de 28 de febrero de 2011. Expediente: 03040611).

De manera reciente, la SIC ha concebido una clasificación que distingue entre la confusión directa, la confusión indirecta y el riesgo de asociación como tres categorías distintas. Al respecto, la SIC, con base en la jurisprudencia del Tribunal Andino de Justicia, hizo la distinción entre estas categorías de confusión en Resoluciones 00028071 y 33746 de 31 de mayo de 2016, en los siguientes términos:

"El riesgo de confusión es la posibilidad de que el consumidor adquiera un producto o servicio pensando que está adquiriendo otro (confusión directa), o que adquiera un producto o servicio pensando que éste tiene un origen empresarial distinto al que realmente 
vincula (confusión indirecta). Por su parte el riesgo de asociación se presenta cuando a pesar de no existir confusión se vincula económica o jurídicamente a uno y otro oferente de los productos o servicios identificados por las marcas respectivas" (Resoluciones 00028071 y 33746 de 31 de mayo de 2016. Superintendencia de Industria y Comercio).

Al respecto, cabe mencionar que el literal a) del artículo 136 de la Decisión 486 establece:

"Artículo 136.- No podrán registrarse como marcas aquellos signos cuyo uso en el comercio afectara indebidamente un derecho de tercero, en particular cuando: a) sean idénticos o se asemejen, a una marca anteriormente solicitada para registro o registrada por un tercero, para los mismos productos o servicios, o para productos o servicios respecto de los cuales el uso de la marca pueda causar un riesgo de confusión o de asociación"

La norma en mención ha dado lugar a varias consideraciones sobre la relación entre el riesgo de confusión- confusión en sentido estricto según una parte de la doctrina ya mencionada- y el riesgo de asociación- confusión en sentido amplio-. Al respecto, ALEMÁN BADEL menciona que, a diferencia de lo ocurrido en Europa, en los países andinos no se dio el debate frente a la diferencia entre las categorías de confusión (Alemán 2012), especialmente sobre la distinción entre el riesgo de confusión y el de asociación. Sin embargo, la interpretación que se ha adoptado por parte de la jurisprudencia del Tribunal de Justicia de la Comunidad Andina y, a su vez, por la jurisprudencia colombiana, es considerar al riesgo de asociación como un tipo de confusión y no como dos figuras independientes.

"considera que la asociación es un tipo de la confusión, por lo que no resulta aplicable sino no se dan los elementos de la confusión, de una parte, semejanza entre los signos y de la otra la relación entre los productos o servicios". En el mismo sentido ESPINOZA, K., "El acto de confusión como acto de competencia desleal y el riesgo de confusión marcaria como infracción a los derechos de la propiedad industrial", en Revista de la Competencia y la Propiedad Intelectual Vol. 3, Núm. 5. 2007. p 131-132, menciona: "Por otro lado, se debe indicar que según este literal se entiende el riesgo de confusión y el riesgo de asociación como dos figuras jurídicas distintas. Si bien un sector de la Doctrina está de acuerdo con esto, existe otro que considera que el riesgo de asociación es la especie, y el riesgo de confusión es el género; es decir, son dos figuras que se relacionan y no se encuentran totalmente desligadas. Consideramos que el riesgo de confusión y de asociación no son dos figuras diferentes, sino más bien se relacionan. Sin embargo, el riesgo de asociación debe ser sancionado cuando ello conduce a un riesgo de confusión. Así, el riesgo de asociación debe considerarse dentro del riesgo de confusión y no tratarse como una figura jurídica independiente, ya que el citado literal a) del artículo 136 de la Decisión 486 nos da a entender como si fueran dos figuras jurídicas distintas."( Tribunal de Justicia de la Comunidad Andina, fallo de 6 de febrero de 2006, proceso 231-IP- 2005).

A pesar de lo anterior, debe hacerse una distinción entre el riesgo de confusión y el de asociación, teniendo en cuenta que el primero está referido a productos y el segundo tiene que ver con la procedencia empresarial, de tal manera que en el primero, el consumidor toma un producto por otro, porque no es capaz de diferenciar el producto imitado del imitador, mientras que en el segundo caso, siendo capaz de diferenciar los productos, considera que tienen el mismo origen empresarial (Portellano 2001). 
Respecto al riesgo de asociación cabe mencionar que en todas las normas europeas se encuentra la coletilla que dice, el riesgo de confusión incluye el riesgo de asociación, y que se refiere o es lo mismo que la confusión en sentido amplio. Sin embargo debe aclararse, que el concepto de la asociación en sentido vulgar, con el uso habitual, común o general que le damos a este término en el lenguaje, no es suficiente no relevante para que se presente al acto de confusión generador de competencia desleal, teniendo en cuenta que la asociación -en sentido vulgar-es información errónea respecto del origen o procedencia empresarial de productos, servicios, actividades o establecimiento, y no por ese simple hecho puede endilgarse la existencia de tal acto; se requiere que exista una relevante evocación o conexión intelectual seria del signo distintivo para poder hacer el juicio y catalogar el acto como de confusión desleal.

Finalmente debe señalarse que en materia de marcas y en materia de competencia desleal no se ha establecido un significado distinto de confusión, en uno y otro ámbito; los autores y la doctrina de los Tribunales han establecido o han empleado el mismo concepto, la misma noción, distinguiendo entre confusión en sentido estricto y en sentido amplio, la primera directa o indirecta.

Sin embargo, el concepto de confusión en materia de marcas y en competencia desleal no puede aplicarse siempre en igual interpretación, como si se tratara de un mismo concepto de aplicación perfecta en un 100\%; existe una gran diferencia, en función de la circunstancia que debe ser tenida en cuenta para determinar la existencia del riesgo de la confusión, en marcas y en competencia desleal, concretándose en una confusión abstracta o normativa que se reserva para las marcas, y una confusión fáctica o casuística que se reserva a la competencia desleal.

\section{Elementos del acto de confusión}

Para entrar en el análisis de la figura de la confusión como acto generador de competencia desleal se requiere identificar qué presupuestos deben concurrir para que se tipifique dicho acto. Para ello debe precisarse que el acto de confusión presenta unos elementos esenciales propios previstos en la normativa, otros elementos creados por la jurisprudencia y otros soportados en la doctrina, agregando que es fundamental para este análisis los pronunciamientos y precedentes españoles, debido a la identidad normativa que se tiene con este país en materia de competencia desleal.

La Corte Suprema de Justicia, Sala de Casación Civil, ha hecho referencia a las etapas que conforman el acto de confusión. Entre estos distingue tres fases, la primera, referente al acto causal capaz de originar confusión y, una segunda fase, referente a la causación efectiva de la confusión y la generación del perjuicio. Sin embargo, tal como lo menciona la Corte, para realizar el reproche de la conducta no es necesaria la generación efectiva de la confusión y la causación real de un perjuicio, por lo que pueden distinguirse dos pretensiones contra el acto de confusión, una que busca hacer cesar el comportamiento, y otra que buscar resarcir el perjuicio en caso de haberse causado. Al respecto la Corte señaló lo siguiente:

“(...) igualmente lo ha expuesto la Corporación, son tres las etapas que pueden constituir el iter de la competencia desleal: la producción de actos capaces de originar confusión, desviación o desorganización; la efectiva confusión, desviación o desorganización como consecuencia de tales actos, y la generación de perjuicios reales y cuantificables con causa en las situaciones anteriores. Desde luego que la acción que ampara la libre competencia, excluyendo los factores de perturbación 
(competencia desleal), procede desde la primera etapa con independencia de la efectiva confusión, desviación o desorganización y de la real causación de perjuicios, pues estos sólo son indemnizables en tanto se hayan producido y sean cuantificables en dinero. De modo que cada etapa ofrece naturalmente la pretensión para debatir, así: en la primera se pretenderá hacer cesar los comportamientos con la potencialidad vista, y en la segunda y tercera, ponerle fin a los efectos nocivos y obtener el resarcimiento del daño padecido." (Sentencia No. 5091 de la Corte Suprema de Justicia, Sala de Casación Civil, de 19 de noviembre de 1999, con ponencia del M.P.: JOSÉ FERNANDO RAMÍREZ GÓMEZ).

Teniendo en cuenta lo anterior, puede considerarse que el acto de confusión se compone esencialmente de dos elementos principales. El primero, una acción desleal que se refiere a un comportamiento idóneo para crear confusión en el consumidor, entre estas se encuentra, como las más comunes, la copia de los signos distintivos, sin embargo, pueden existir otras conductas que puedan configurarse como tal. Por otra parte, se encuentra un resultado o la generación del riesgo de confusión, este último bajo el entendido que no es necesario la producción de una confusión real y efectiva, pues solo basta con que la conducta tenga idoneidad objetiva para producir la confusión (Martínez 2009).

\section{Pronunciamiento jurisprudencial en Colombia sobre el acto de confusión}

En el caso ESSO-TERPEL, cuya controversia se suscitó por las ventas de combustibles y lubricantes Terpel al amparo de los avisos, signos y emblemas de su competidora 'Esso Colombiana Limited, la Corte Suprema de Justicia en Sentencia Nº 054 de 2002 frente a los actos de confusión que generaba la mixtura de marcas y colores de las dos empresas en una estación de servicio en principio de propiedad de TERPEL y posteriormente de ESSO, consideró lo siguiente:

"Es desleal el comportamiento, aun en perjuicio propio, de mantener los signos distintivos y marcas de la competencia que utilizó anteriormente el inmueble comercial, creándose una coexistencia de elementos de identificación por cuanto carece de eficacia para eliminar la confusión en el consumidor el hecho de que las enseñas y colores que dominaban en el punto de venta y podían atraer la clientela, eran sin ambages los de la Esso" (Sentencia No. 6869 de la Corte Suprema de Justicia. Sala de Casación Civil, de 9 de abril de 2002).... "Hoy está fuera de duda, pues, que al consumidor hay que garantizarle las preferencias y su libre escogencia, estableciendo los mecanismos que lo pongan a cubierto de todo aquello que constriña su voluntad, y de ahí que todos a una convienen que hay que proscribir desde los métodos aviesos, hasta los meramente delusivos o engañosos. Mecanismos esos que ya forman parte del ordenamiento jurídico patrio, y, como ahora es muy de notar, la protección que deviene como consecuencia de reprimir los actos de competencia desleal como los que se juzgan (...) "Al haberse sobrepuesto la publicidad de Terpel sobre los elementos de identificación que la Esso tenía en la estación en las condiciones que reflejan las pruebas aludidas, se creó una mixtura inaceptable de marcas y colores de por sí suficiente para confundir, desorientar al consumidor en general y desviar la clientela. " (Sentencia No. 6869 de la Corte Suprema de Justicia. Sala de Casación Civil, de 9 de abril de 2002). 
En la sentencia anterior emitida por la Corte Suprema de Justicia en el año 2002, se evidencia la relevancia que enmarca el concepto de consumidores y la institución de la competencia. El juicio de reproche que hace la Corporación deja entrever que es inaceptable que se realicen actos en el mercado con la finalidad de confundir y desorientar al consumidor, generando una desviación ilegítima de la clientela, independientemente que el comportamiento del actor concluya en perjuicio propio. Es claro, que la competencia y libre competencia está garantizada constitucionalmente, por ello, la finalidad concurrencial de los agentes del mercado debe estar sometida únicamente al esfuerzo propio, al empeño propio, a la calidad propia de sus productos y servicios, y no como lo dijo la Corte, a la caída artificial del rival.

\section{El acto de imitación desleal y su diferenciación con el acto de confusión}

La normativa colombiana no prevé de forma expresa y con claridad la diferencia entre los actos de confusión e imitación generadores de competencia desleal, salvo su enunciación en artículos diferentes, razón por la cual, se han generado interpretaciones erróneas al momento de formular las demandas de competencia desleal (Barona 1999). Debido a ello, en la práctica jurídica y de litigio en Colombia, los apoderados y abogados han empezado a invocar todos los actos de competencia desleal que ejemplificativamente se mencionan en la Ley y, así mismo, apelan simultáneamente a la cláusula de prohibición general, generando un efecto negativo de congestión e imposibilidad de aplicar el principio de celeridad, en la medida en que la autoridad competente debe referirse a cada uno de los actos solicitados como pretensión, desestimando casi siempre, la mayoría de actos por no ser pertinentes al caso. Esta práctica es la manera como los abogados se aseguran que se evacúe el estudio de todos los actos, y así no pecar en la interpretación y en la posible indebida formulación de pretensiones, situación que no puede ser considerada como sana para el sistema judicial.

Para la correcta interpretación del acto de confusión, de manera que se evite cualquier relación o duda respecto de la imitación como acto autónomo generador de competencia desleal, es preciso señalar que hoy ya ha quedado zanjada cualquier clase de incertidumbre o duda sobre el particular, toda vez que jurisprudencialmente en España, se han concretado las diferencias entre uno y otro acto, al decidirse y reiterarse que la confusión aplica a los medios que identifican un producto (signos distintivos), mientras que la imitación por su parte, como acto independiente, se refiere a los productos o servicios de un tercero.

A tal efecto, mediante sentencia del Tribunal Supremo Español de 2007 se estableció con ponencia del Sr. D. Francisco Marín Castán, lo siguiente respecto a lo consagrado en la Ley de competencia desleal española sobre el acto de confusión y el acto de imitación:

"Por su parte la doctrina científica dominante asigna al artículo 6 las creaciones formales o signos distintivos y al artículo 11.2 las creaciones materiales, comprendiendo tanto los productos como las formas tridimensionales, aunque éstas puedan ser registradas como marca. Este diferente ámbito de aplicación lo justifican los autores, además de por el antecedente que representó el Anteproyecto ya mencionado, por la regulación separada de los actos de confusión y de los actos de imitación; por la correspondencia, en el texto del artículo 6, entre nombres comerciales ("actividad"), marcas ("prestaciones") y rótulos de establecimiento 
("establecimiento"); y sobre todo, porque la "inevitabilidad", contemplada por la Ley en el artículo 11.2 pero no en el 6, la cual debe entenderse como imposibilidad de que no se produzca el riesgo de asociación entre dos prestaciones, sólo puede predicarse de los productos y formas tridimensionales."

En el mismo sentido, el Tribunal Supremo de España, Sala I de lo Civil, en providencia del 20 de mayo de 2010, en interpretación de lo preceptuado en la Ley de competencia desleal, determinó que el acto de confusión es sustancialmente diferente al acto de imitación, en el sentido que el primero, se refiere a las creaciones formales y el segundo, a las creaciones materiales, al respecto mencionó el Tribunal:

"En efecto, al identificar la norma el objeto de la confusión del consumidor con " la actividad, las prestaciones o el establecimiento ajenos ", pone de manifiesto que se está refiriendo a los medios de identificación o presentación de la empresa, de las prestaciones o de los establecimientos de otro agente económico en el mercado, mientras que el artículo 11, lo hace a la imitación de las iniciativas empresariales y de las prestaciones ajenas, entendidas éstas en el sentido de creaciones materiales sentencias de 11 de mayo de 2.004, 7 de julio de 2.006, 4 de marzo de 2.010 -.Por ello hemos declarado en numerosas ocasiones que la confusión contemplada en el artículo 6 tiene por objeto las creaciones formales lanzadas al mercado, esto es, los instrumentos o medios que llevan hasta el consumidor información sobre la actividad, las prestaciones o los establecimientos de otro participante en aquel ámbito - sentencia de 23 de julio de 2.010 -".

Esta doctrina, según la cual el acto de confusión o riesgo de confusión generador de competencia desleal aplica solo cuando se ven involucradas creaciones formales, es decir, signos distintivos, y no creaciones materiales (productos), ha sido recogida por la Superintendencia de Industria y Comercio de Colombia en sus decisiones de carácter jurisdiccional en la materia, pese a que la normativa nacional al respecto no lo menciona ni de manera textual ni de forma tácita, máxime cuando los conceptos de la actividad, las prestaciones mercantiles o el establecimiento involucran en nuestro parecer no solo las creaciones formales, sino también las materiales, aspectos que, como se ha mencionado, crea situaciones confusas de interpretación que podrían llevar a la indebida invocación de pretensiones procesales en la respectiva demanda de competencia desleal, que eventualmente terminan con su desestimación.

En relación con lo anterior, se tiene que, en Colombia, la Superintendencia de Industria y Comercio de Colombia, también ha sostenido que el acto de confusión guarda relación con los signos distintivos y en general los elementos que permiten identificar el origen empresarial de un producto o servicio ofrecido en el mercado, es decir sobre aspectos o creaciones formales, al respecto señaló esta entidad:

“El objeto del acto desleal de confusión está constituido por los medios de identificación empresarial, esto es, los signos distintivos y, en general, los elementos que permitan establecer el origen empresarial de una determinada prestación mercantil y diferenciarla de otras ofertas que concurren al mercado, ejemplo de lo cual es la presentación de los empaques de un producto (creación formal).

Ahora bien, para la realización del acto de confusión es frecuente la reproducción de los elementos distintivos de un producto competidor, pues salta a la vista que la inevitable existencia de un riesgo de confusión o de aprovechamiento de la reputación ajena como consecuencia de un acto de imitación 
puede predicarse de productos o servicios en sí mismos (creaciones materiales), en razón a que la manera en que un producto se presenta en el mercado (los signos distintivos empleados, la presentación del artículo o cualquier otra creación formal) es -en línea de principio- modificable para evitar que genere los aludidos efectos perjudiciales en aquel escenario . (...)

Sin embargo existe la regla general de libre imitación de productos o servicios que encuentra fundamento en que esa conducta, siempre que no esté acompañada de los elementos atributivos de deslealtad, es considera pro-competitiva en la medida en que elimina -en lo posible y razonable- restricciones a la libre concurrencia, promueve la eficiencia del mercado, genera un ambiente competitivo que motiva a los diversos oferentes a innovar con el propósito de superar a sus competidores $y$, en consecuencia, brinda a los consumidores la posibilidad de elegir entre distintas ofertas de bienes y servicios en atención a cantidades, calidades y precios, efectos que obviamente no se pueden predicar de la reproducción de signos distintivos o de cualquier otro medio de identificación empresarial, dada la alta probabilidad de que este comportamiento, al contrario, dificulte la labor de diferenciación de las distintas ofertas disponibles en el mercado". (Sentencia No. 001 de 2011 de la Superintendencia de Industria y Comercio de Colombia, de 12 de enero de 2011, Expediente 04060765).

\section{Conclusión}

A manera de conclusión podemos indicar que el acto de confusión generador de competencia desleal, como uno de los más frecuentes dentro del mercado colombiano, no integra dentro de su descripción normativa, los elementos necesarios para una valoración simple y objetiva. Precisamente para lograr una hermenéutica correcta, se requirió acudir a otras fuentes como la jurisprudencia y la doctrina, con la finalidad de establecer la integralidad de sus elementos, que permitieran una identificación más objetiva y que a su vez, con una aplicación de un método sistemático, lograr establecer la principal diferencia con el acto de imitación, acto este con el cual frecuentemente se generan discusiones en los espacios judiciales.

Es así como una de las principales dificultas al momento al analizar los aspectos fácticos de una situación particular ha sido el poder identificar y diferenciar el acto de confusión del acto de imitación, y en este sentido, definir las reclamaciones jurisdiccionales que correspondan. Atendiendo a la doctrina española, según la cual el acto de confusión o riesgo de confusión generador de competencia desleal aplica solo cuando se ven involucradas creaciones formales, es decir, signos distintivos, y no creaciones materiales (productos), ha sido recogida por la Superintendencia de Industria y Comercio de Colombia en sus decisiones de carácter jurisdiccional en la materia, teniéndose hoy ya zanjado, que el acto de confusión o riesgo de confusión constitutivo de competencia desleal está vinculado siempre con signos distintivos y formas identificativas de productos y servicios, principalmente las marcas; mientras que el acto de imitación generador de competencia desleal estará relacionado, ya no con los signos distintivos, sino con las creaciones materiales, es decir los productos, de manera que jurídicamente no se podrá invocar la existencia de un acto de confusión o riesgo de confusión, si esta situación surgió exclusivamente por la vinculación confusoria sobre un producto; así, el acto correcto a invocar sería el de imitación; por lo que, al contrario, si la situación confusoria tienen su origen exclusivo en la relación con un signo distintivo, como una marca, nombre comercial o lema, el acto a demandar estará sustentado en la confusión y no en la imitación como actos independientes. 
Por otra parte, debemos entender el acto de confusión (y para su existencia), como un tipo que se cataloga como de peligro y no de resultado, en la medida en que permite su configuración o juicio de reproche con la sola determinación del riesgo, lo que en otras palabras puede entenderse, como la no exigencia de la verificación material de la confusión para su enjuiciamiento, en la medida en que basta la sola existencia del riego de confusión. Claro está, dicho riesgo de confusión debe estar sustentando en una conducta idónea e inequívocamente dirigida a la consolidación de la confusión.

Respecto del acto de confusión generador de competencia desleal, se han establecido dos categorías a saber: la confusión directa y la confusión indirecta, siendo la primera la situación por medio de la cual el consumidor adquiere un producto pensando que está adquiriendo otro; por su parte, la confusión indirecta se presenta cuando el consumidor, pudiendo diferenciar los productos o servicios, les otorga un origen empresarial diferente al real. Ahora, la configuración del riesgo de asociación, que se presenta cuando el consumidor reconoce la diferencia entre los productos o servicios de que se trate y su distinto origen empresarial, pero considera que existe un vínculo jurídico entre las dos empresas.

Importante reiterar, que estas categorías de confusión, directa, indirecta y riesgo de asociación generadores de competencia desleal, son reprochables y, por tanto, dan lugar a la interposición de la acción judicial de competencia desleal.

Finalmente, con el análisis aquí presentado, se espera un mayor rango de identificación de los actos de competencia desleal en el mercado, con miras, no solo a su sanción judicial, sino por el contrario, a un mayor conocimiento de la figura por parte de los que participan en el mercado colombiano, con el fin de evitar su incursión en lo máximo posible.

\section{Referencias}

Alemán, M., (2012). Las marcas y las patentes en el marco del proceso de integración de la comunidad andina. Tesis doctoral.

Barona, S.,(1999) Competencia Desleal. 2ª Ed. Valencia: Tirant lo Blanch.

Cardona, A., (2009) Marco legal de la competencia en Colombia. Buenos Aires: El Cid Editor - apuntes.

Fernández, C., Otero, J., y Botana, M. (2013) Manual de Propiedad Industrial. 2a. Ed., Madrid, Marcial Pons.

Martínez, S. (2009), Comentario practico a la Ley de Competencia Desleal. Madrid: Tecnos.

Massaguer, J., (2017) Transcripción de la conferencia "Confusión en Derecho de marcas y de Competencia Desleal", del Tercer Congreso Internacional de Derecho de los Mercados realizada en Medellín, Colombia, el 28 de septiembre de 2017.

Portellano, P. (2001) La imitación en el Derecho de la Competencia Desleal. Madrid: Civitas.

Uria, R., y Menendi, A., (2006) Curso de derecho mercantil. Empresario, establecimiento mercantil y actividad empresarial. Derecho de la competencia y de la propiedad industrial e intelectual. Derecho de sociedades. Thomson- Civitas.. 
Velandia, M., (2001) Competencia desleal por uso de signos distintivos, en Revista de propiedad inmaterial. Núm. 2.

Velandia, M., (2008) Derecho de la competencia y del consumo. Bogotá: Universidad Externado.

\section{Sentencias}

República de Colombia. Superintendencia de Industria y Comercio. Sentencia Nº01 de 2006, de 4 de enero de 2006, Expediente No. 03081970.

República de Colombia. Superintendencia de Industria y Comercio Sentencia N001 de 2011, de 12 de enero de 2011, Expediente 04060765.

República de Colombia. Superintendencia de Industria y Comercio Sentencia No. 006 de 28 de febrero de 2011. Expediente: 03040611.

República de Colombia. Corte Suprema de Justicia. Sala de Casación Civil, Sentencia No. 6869 de la de 9 de abril de 2002.

Tribunal de Justicia de la Comunidad Andina, fallo de 6 de febrero de 2006, proceso 231-IP- 2005. 